Dermatologica, 1984;168(suppl. 1):1-3

\title{
Contents, Vol. 168, Supplement 1, 1984
}

\section{Contents}

Preface

Weiner, $\mathrm{M} \quad 5$

In vitro Models Reflecting the Action of Strong Acids on Integumental Tissue (with 1 colour plate)

Weiner, M 7

Preclinical Evaluation of Acid Products for Treatment of Solid Experimental Skin Tumors

in Mice

Kreis. W

Histopathologic and Electron Microscopic Studies of the Effects of Solcoderm on Normal

Epidermis and Superficial Cutaneous Tumors

Cesarini, J.-P 15

Double-Blind Study of Variables Influencing the Clinical Effects of Solcoderm

Weiner, M; Semah, D; Schewach-Millet, M 26

An Overview of Clinical Experience with Solcoderm

Labhardt. W.C 31

Solcoderm in the Treatment of Solar and Seborrheic Keratoses

Feuerman, E.J.; Katzenelson, V.; Halevy, S 33

Solcoderm as a Tool for the Plastic Surgeon. The Treatment of Verrucae

(with 2 colour plates)

Hettich, R 36

Cumulative Experience with Solcoderm in the Treatment of Basal Cell Epithelioma

Schewach-Millet, M; Azizi, E.; Semah, D 43

Solcoderm Treatment of Epidermal Growths Including Intradermal Nevi

Haim. S.; Cohen, A 46

Topical Treatment of Condylomata acuminata with Solcoderm

Brokalakis, J.; Goumouzas, N.; Varelzidis, A 49

Treatment of Naevi and Warts by Topical Chemotherapy with Solcoderm (with 1 colour plate)

Burri. P 52

Differential Aspects of Solcoderm Therapy as a Function of Dermatologic Diagnoses

Binet. O.; Cesaสni, J.-P.; Bruley, C; Aron-Brunetière, R 58

Long-Term (5-8 Years) Follow-Up of Solcoderm-Treated Malignant Skin Tumors

Ravid, M.; Sohar, E.; Krispin, M.; Mardi, S.; Semah, D 63

Author Index 66

Subject Index 67 